\title{
Mediações em tempos híbridos: entre pátrias e revoluções
}

Mediations in Hybrid Times: between

Homelands and Revolutions

\section{Marco Morel}

Professor no Departamento de História da Universidade do Estado do Rio de Janeiro (IFCH / UERJ Rio de janeiro / Brasil)

e-mail: marco.morel@pesquisador. cnpq.br

\section{Resumo}

A presença de François-René de Chateaubriand como agente entre "Dois Mundos", sobretudo diante das questões das independências e do tráfico de escravos entre Américas e Europa, remete às concepções de pátria, colônia e independência, questões que são recolocadas como centrais nas relações entre Estados na Europa, no contexto de busca de estabilização política e social no período pós-Revolução Francesa.

\section{Abstract}

The presence of François-René de Chateaubriand as an agent between "Two Worlds", namely in face of the issues like the independencies and the slave traffic between the Americas and Europe, refers to the conceptions of homeland, colony and independence, issues that are restored as central to the relations among the states in Europe, in the context of the search for social and political stabilization during the Post-French Revolution period.

\section{Palavras-chave}

revolução, liberalismo, idéias políticas, tráfico negreiro, Independência, relações internacionais

\section{Keywords}

revolution, Enlightenment, political ideas, slave trade, Independence, internal relations 
1

MOREL, Marco. Pátrias polissêmicas: República das Letras e imprensa na crise do Império português na América. In: KURY, Lorelay (org.). Iluminismo e Império no Brasil. 0 Patriota (18131814). Rio de Janeiro: Fiocruz, 2007. p.67-102.
0 texto "Entre tempos e mundos: Chateaubriand e a outra América", de Wilma Peres Costa, é tão instigante quanto o tema nele estudado. 0 olhar sobre aqueles tempos consegue uma perspectiva de amplitude, da história em grandes traços com cenários épicos, paradoxais e incertos, como habitualmente são os tempos de crise. 0 artigo tem, inicialmente, este mérito de, em tempos historiográficos de especialização (ou "migalhas", como preferem alguns), manter a dimensão macro sem perder a articulação com o recorte temático e cronológico escolhido. Elaborado à maneira abrangente das aulas dos catedráticos, incorpora também aquisições mais recentes da história política. Dialogando e partindo das perspectivas estruturais, sistêmicas ou socioeconômicas, abre-se para o tempo da curta duração, da análise do pensamento político, dos conceitos, da consciência e ação dos protagonistas e da dinâmica da aceleração do tempo histórico. A conhecida frase de Chateaubriand sobre os restauracionistas em geral e Fernando VII em particular, citada em seu artigo, só pode ser aplicada à autora pela metade: nada esqueceu, mas se renovou no eterno aprendizado da pesquisa e docência. Trata-se, pois, da contribuição de alguém que domina o ofício de historiador, pela maneira exemplar que envolve segurança, rigor, nuances e polissemias com os quais trata as palavras, episódios e personagens.

É, pois, com satisfação que aceitei o desafio de apreciar um trabalho com tais características. $E$, na condição de pesquisador do período e de temáticas próximas, aprendi bastante com o artigo. Minha tentativa de contribuição, pois, será baseada em dois procedimentos. Apontar os aspectos inovadores e a contribuição para o conhecimento e, também, buscar alguns pontos e questões que poderiam servir de complemento ao que foi apresentado, sobretudo a partir de minha própria perspectiva e pesquisas realizadas.

Quanto à discussão conceitual apresentada inicialmente, com destaque para os sentidos polissêmicos de nação, penso em agregar o conceito de pátria. Se é verdade que a mudança do significado tradicional de nação (de étnico cultural) para o moderno (cívico político, "externo" e "interno") foi essencial, como assinala a autora, é possivel avaliar que houve uma migração do conceito também caleidoscópico de pátria (que até e durante a Revolução Francesa tinha forte sentido politizado) para o de nação. Apesar dos significantes não serem os mesmos, os significados de pátria acabaram se transmutando para os de nação. Como já assinalava R. Bluteau em seu Vocabulário de 1712, pátria não era compreendida apenas como local de nascimento mas, sim, como: local de nascimento (cidade, província ou reino), local de escolha de moradia (que ficaria conhecido como pátria de adoção), espaço de universalidade (além das fronteiras territoriais), espaço abstrato de liberdade intelectual e utopia política e, finalmente, como espaço político de atuação e virtude?

Quanto ao conceito de colônia, o que me parece mais instigante é justamente indagar até que ponto o sentido pejorativo do que viria a ser chamado de colonialismo surge exatamente na (e a partir da) época tão bem estudada por Wilma Costa. Mesmo que algumas formulações do abade Raynal fossem bastante contundentes quanto à presença dos europeus na América, pode-se questionar até que ponto ele formula claramente a noção de colônia como naturalmente antagonista de uma metrópole, idéia que só viria a aparecer com mais clareza em outro contexto, durante e após os processos de Independência da América ibérica, através das análises de 
RAYNAL, Guillaume-Thomas François. 0 Estabelecimento dos Portugueses no Brasil. Rio de Janeiro/Brasilia: Arquivo Nacional/UnB 1998; DE PRADT, Dominique. Des colonies et de la Révolution actuelle de l'Amérique. Paris: Bechet / Egron, 1817; para uma abordagem inicial do pensamento de Pradt sobre as independências na América, ver MOREL, Marco. A Independência no papel: a imprensa periódica. In: JANCSÓ István (org.). Independência: História e Historiografia. São Paulo: Hucitec/ Fapesp, 2005. p.617-626.

3

GUERRA, François-Xavier. A nação na América espanhola: a questão das origens. Maracanan, vol.1, n.1, p.9-30, 1999/2000; Idem. Modernidad e independencias. Ensayos sobre las revoluciones hispánicas. Madri: Mapfre, 1992.

ROSANVALON, Pierre. Le moment Guizot. Paris: Gallimard, 1992. outro abade, o De Pradt². Após as independências nacionais americanas, o vocábulo colonização persiste, mas com sentido de ocupação racional de territórios e vinda de imigrantes estrangeiros.

A partir destas questões, lembro aqui duas contribuições de FrançoisXavier Guerra, através de duas categorias que ele forjou para o contexto: patriotismo imperial e hibridismo cultural e político ${ }^{3}$. Deste modo, muitas das manifestações de tipo patriótico que antecedem as Independências da América ibérica poderiam ser compreendidas sob tal ótica. A passagem do patriotismo imperial para a soberania nacional faria parte justamente da construção de novas referências políticas e culturais naquelas sociedades em transformação.

A própria idéia de que espanhóis e portugueses compunham uma "raça degenerada", presente no pensamento francês (inclusive na obra de Raynal), aparece formulada por Chateaubriand no momento chave das Independências americanas e seria, em boa medida, utilizada nos subseqüentes movimentos de afirmação das novas nacionalidades.

Quanto ao hibridismo cultural e político (que não se confunde com as idéias de "mestiçagem"), talvez seja mais uma opção para se compreender a perspectiva e atuação de François-René de Chateaubriand, na medida em que, como assinala Wilma com sensibilidade e exatidão, ele transitava entre tempos e mundos. É verdade que o hibridismo tão característico deste período não era homogêneo (alguns mais para o antigo, outros mais para o moderno) e Chateaubriand constituiu sua própria e original "mistura".

Neste sentido, é fecunda a assimilação apresentada por Wilma sobre as viagens (que implicam em deslocamentos e decalagens, de tempo e espaço), articulando-as com as visões de Raynal sobre os Novos Mundos e com o pensamento de Tocqueville sobre a democracia na América (do Norte), sem fazer a associação, muito mais freqüente, da comparação com autores que formularam críticas mais contundentes ao processo revolucionário, como J. de Maistre e L. de Bonald. Embora não esteja no foco da autora uma análise propriamente do pensamento político de Chateaubriand, não deixa de ser tentador aproximar tal perspectiva de viagem ao marcante (na época) relato e reflexões de Volney sobre as ruinas dos impérios, publicadas no mesmo ano da ida de Chateaubriand à América do Norte. Do mesmo modo que as considerações de E. Burke sobre a Revolução em França, na qual o autor insiste, como é sabido, na importância da tradição dos costumes e da civilização longamente construída e ameaçada pelos horrores da Revolução. No sentido prospectivo, pode-se imaginar que Chateaubriand pertencia à mesma linhagem política de um F. Guizot, por exemplo (ainda que um fosse oposicionista e outro expoente da Monarquia de Julho), cujo liberalismo monárquico, constitucional e conservador pregava harmonia entre as novas liberdades, com o encerramento do processo revolucionário e a consolidação de um Estado forte e centralizador ${ }^{4}$. Sem contar a discussão sobre as liberdades modernas e antigas empreendidas por outro liberal pós-Revolução Francesa, Benjamin Constant, cujas concepções de Estado e liberdade se demarcavam de Guizot.

Outro mérito do trabalho de Wilma é colocar a escravidão (com destaque para o tráfico atlântico) como ponto central das relações entre os Estados europeus, não aspecto secundário ou ramo delgado de frondosa árvore. Através da ação diplomática de Chateaubriand estudada por Wilma percebemos que, mesmo sem o trabalho escravo ter o mesmo peso nas sociedades européias e americanas, este assunto criava tensões e impasses, 
ROSANVALON, Pierre. Le moment Guizot. Paris: Gallimard, 1992.

5

BENOT, Y. e D'ORIGNY M. (org.). Rétablissement de l'esclavage das les colonies françaises. 1802. Aux origines de Haiti. Paris: Maisonneuve, 2003.

6

BENOT, Y. La modernité de l'esclavage. Essai sur la sérvitude au coeur du capitalisme. Paris: sendo motivo de embates diplomáticos diretos entre Inglaterra e França. Os chamados problemas colonial e escravista estavam na base dos limites e das possibilidades de reestruturação dos impérios europeus em suas relações com o Novo Mundo.

Faz parte desta questão ao mesmo tempo colonial e escravista o tão lembrado exemplo de São Domingos, isto é, da rebelião de escravos iniciada em 1791 e que desembocaria na Independência do Haiti em 1804. Anote-se que as resistências francesas à perda desta colônia foram intensas, com desperdício de vidas humanas e despesas avultadas. E foi somente dois anos depois da saída de Chateaubriand do ministério dos Negócios Estrangeiros que a França reconheceria tal Independência, cobrando uma indenização astronômica cujo pagamento ajudaria a manter a situação de pobreza e violência que ainda hoje marca o Haiti5.

Neste sentido, os pronunciamentos de Chateaubriand assinalados e analisados por Wilma não podem ser considerados dos mais progressistas, nem originais - do ponto de vista da escravidão. Inclusive pela comparação com pensamento de franceses contemporâneos, como o abade Grégoire, notório abolicionista e defensor da Independência do Haiti, como pelo já citado abade De Pradt, que formulou uma visão mais sofisticada sobre o assunto: seria mais propício, segundo este, preparar gradualmente uma emancipação das colônias e da escravidão, para evitar que os sucessos (como se dizia) de São Domingos se espalhassem por outras partes. Diante do protagonismo escravo encarnado pela Revolução do Haiti, De Pradt propunha duas atitudes: silêncio e ocultação ou, então, execrar os horrores de tais episódios. Verdade que os testemunhos de Chateaubriand citados fazem parte de sua ação diplomática no calor dos acontecimentos, não de uma reflexão mais elaborada. E que do ponto de vista estritamente político, Chateaubriand não pode ser taxado de retrógrado, pois defendia a monarquia constitucional e os princípios básicos do liberalismo, como a representatividade parlamentar e o constitucionalismo, ainda que numa vertente que privilegiava a soberania do monarca6.

A complexidade do conceito de revolução, seja visto como horror a ser repudiado, seja como processo inelutável resultante do progresso, compartilhada pelo liberalismo que sucedeu a Revolução Francesa e a Constituição de Cadiz, e que seria a base do juste milieu e da idéia de moderação, já estava presente em Chateaubriand, como bem mostra Wilma. Em termos esquemáticos, pode-se apontar três posições básicas sobre a idéia de revolução nestas primeiras décadas do XIX: negar e combater; aceitar como parte do passado, assimilar e colocar um ponto final; considerar somente como ponto de partida para a continuidade de futuras revoluções.

A partir da análise elaborada por Wilma, pode se compreender a posição de Chateaubriand como intermediária entre a primeira e a segunda, combatendo a terceira. Os rótulos são úteis, mas também precários, ainda mais num tempo de aceleração do tempo, crises, incertezas e revoluções. Se a definição clássica de contra-revolucionário, embora pertinente em alguns aspectos, não basta para dar conta da riqueza do pensamento de Chateaubriand, do mesmo modo catalogá-lo como liberal, ainda que conservador, embora cabivel, mas com nuances.

Duas categorias, mediação e metamorfose, poderiam integrar a compreensão da presença deste inter-mediário entre mundos e tempos, na feliz formulação de Wilma Costa. A Independência do Brasil, por 
La Découverte, 2003; Idem. Les Lumières, I'esclavage et la colonisation. Paris: La Découverte, 2005

PIMENTA, João Paulo Garrido. O Brasil e a América espanhola (1808-1822). Tese de Doutorado, São Paulo: Departamento de exemplo, ainda que alguns considerem como fruto das Luzes ou "novas idéias", teve a mediação política e cultural da Restauração Francesa, que de alguma maneira filtrava estes fluxos e vertentes, reelaborando-os. Chateaubriand, intelectual e chefe da diplomacia francesa entre 1822 e 1823, teve papel importante neste momento, ponto de partida para a construção nacional brasileira.

A noção de "influência" para se compreender estas relações entre os continentes e seus mundos já está desgastada. Além de atravessados por mediações, as idéias, modelos politicos e ações concretas passam por expressivas metamorfoses geradas, sobretudo, pela presença dos supostos "influenciados", que recebem, relêem, ressignificam e reagem de acordo com suas próprias perspectivas.

Enfim, estes rápidos comentários sobre o artigo "Entre tempos e mundos: Chateaubriand e a outra América" não dão conta da riqueza da reflexão elaborada por Wilma Costa e deixam de lado temas cruciais, como a presença e as reflexões de Chateaubriand sobre questão ibérica e das Américas (do Norte e espanhola, esta como objeto também dos trabalhos de João Paulo Pimenta ${ }^{7}$ ), sobre as formas de governo, sobre passado e futuro, entre outros pontos.

Sem se propor a um enfoque biográfico, as reflexões de Wilma Costa sobre a vida e a obra de Chateaubriand nos apresentam uma trajetória ao mesmo tempo articulada e solitária, grandiosa e marginal, com a instabilidade e a constância da amplidão dos mares: do além túmulo, ainda hoje, o mausoléu do personagem se encontra pousado, ousado, isolado e épico nas rochas batidas pelas ondas na praia de Saint Malo, um dos portos de chegada e partida entre o Velho e o Novo Mundo.
História, Faculdade de Filosofia, Letras e Ciências Humanas, Universidade de São Paulo, 2004.

Recebido para publicação em abril de 2010 Aprovado em abril de 2010 